\title{
Design, Analysis, and Control of DC-Excited Memory Motors
}

\author{
Chuang Yu and K. T. Chau, Senior Member, IEEE
}

\begin{abstract}
In this paper, a new type of memory motors, namely the dc-excited memory motor, is proposed and implemented. The concept of dc-excited memory is due to the nature that the magnetization level of permanent magnets (PMs) in the motor can be regulated by a temporary dc current pulse and be automatically memorized. Based on an outer-rotor doubly salient motor structure, the proposed dc-excited memory motor can offer effective and efficient online air-gap flux control. Hence, it possesses the advantages of mechanical robustness, high efficiency, and wide constant power operation region. Both simulation and experimentation are carried out to verify the validity of the proposed motor.
\end{abstract}

Index Terms-DC-excited, doubly salient, flux control, flux mnemonic, memory motor, permanent magnet (PM) motor.

\section{INTRODUCTION}

D UE to high efficiency and high power density, permanent magnet (PM) motors are widely accepted for industrial and vehicular applications [1], [2]. Because of the fixed PM excitation, they cannot easily perform air-gap flux control. For those sinusoidal-fed PM motors, various vector control techniques have been developed, which basically utilize the negative $d$-axis current to weaken the air-gap flux [3], [4]. For those rectangular-fed PM motors, the air-gap flux can be weakened by purposely advancing the conduction angle or employing the transformer electromotive force (EMF) to counteract the rotational EMF at high speeds [5], [6]. However, they both rely on sophisticated control means.

With the advent of doubly salient PM (DSPM) motor, in which both the PMs and armature windings are located in the stator, the air-gap flux control can be performed in a simpler way [7], [8]. By incorporating a dc field winding in the stator, the hybrid-field DSPM (HF-DSPM) motor can enable both flux-weakening and also flux-strengthening [9], [10]. Nevertheless, the corresponding dc field winding needs to be continually energized, thus degrading the motor efficiency.

Manuscript received March 20, 2010; revised August 23, 2010; accepted September 17, 2010. Date of publication December 13, 2010; date of current version May 18, 2011. This work was supported by a research grant from the Research Grants Council, Hong Kong Special Administrative Region, China, under Project No. HKU 710710E. Paper no. TEC-00129-2010.

C. Yu was with the Department of Electrical and Electronic Engineering, University of Hong Kong, Pokfulam, Hong Kong, China. He is now with Johnson Electric, Shatin N.T., Hong Kong, China (e-mail: chuangyu @eee.hku.hk).

K. T. Chau is with the Department of Electrical and Electronic Engineering, University of Hong Kong, Pokfulam, Hong Kong, China (e-mail: ktchau@eee.hku.hk).

Color versions of one or more of the figures in this paper are available online at http://ieeexplore.ieee.org.

Digital Object Identifier 10.1109/TEC.2010.2085048
The memory motor, or called flux-mnemonic PM motor, is a new class of flux-controllable PM motors, which can directly regulate the magnetization level of PM excitation [11]-[13]. The concept of memory is due to the nature of the aluminumnickel-cobalt (AlNiCo) PMs in the motor that can be online magnetized or demagnetized to various magnetization levels and then be memorized automatically. Therefore, this kind of flux control can solve the problem of continual excitation of the HF-DSPM motor. In [11], the memory motor adopted a conventional sinusoidal-fed PM motor structure, which utilized the $d$-axis armature current to perform magnetization or demagnetization. Thus, this so-called ac-excited memory motor still suffers from the use of complicated vector control. Also, its motor structure suffers from the lack of mechanical integrity and the possibility of accidental demagnetization due to armature reaction. In [12] and [13], the idea of using a dc field winding for the HF-DSPM motor was extended to the memory motor. It incorporated a small dc magnetizing winding to produce the magnetizing current for direct PM magnetization, hence avoiding the complicated current control. Nevertheless, this so-called dc-excited memory motor has only been preliminarily assessed by simplified simulation.

The purpose of this paper is to propose and implement a new dc-excited memory motor. Design, analysis, and control of the proposed motor will be discussed. Both simulation and experimentation will be given to illustrate the features and to verify the validity of the motor.

Different from our previous works [12], [13], which focused on machine design for different applications, the contributions of this paper are to develop the whole motor system, with emphasis on the control strategy, which can offer effective and efficient online control of PM magnetization and hence the airgap flux density. Actually, the implementation of speed control and flux control for the dc-excited memory motor is absent in the literature. Moreover, a piecewise-linear hysteresis model of the AlNiCo PM is newly proposed and incorporated with the finite-element method (FEM), which enables it to perform both transient and steady-state analysis of the motor accurately.

\section{Motor DesigN}

\section{A. Aluminum-Nickel-Cobalt Permanent Magnet}

When the AlNiCo PM material was invented in 1930s, it was widely employed for PM motors due to its excellent remanence, high thermal stability, and high chemical stability. However, in a conventional PM motor, PMs were expected to have both a linear demagnetization curve with a superposed recoil line so as to provide stable performance under normal 


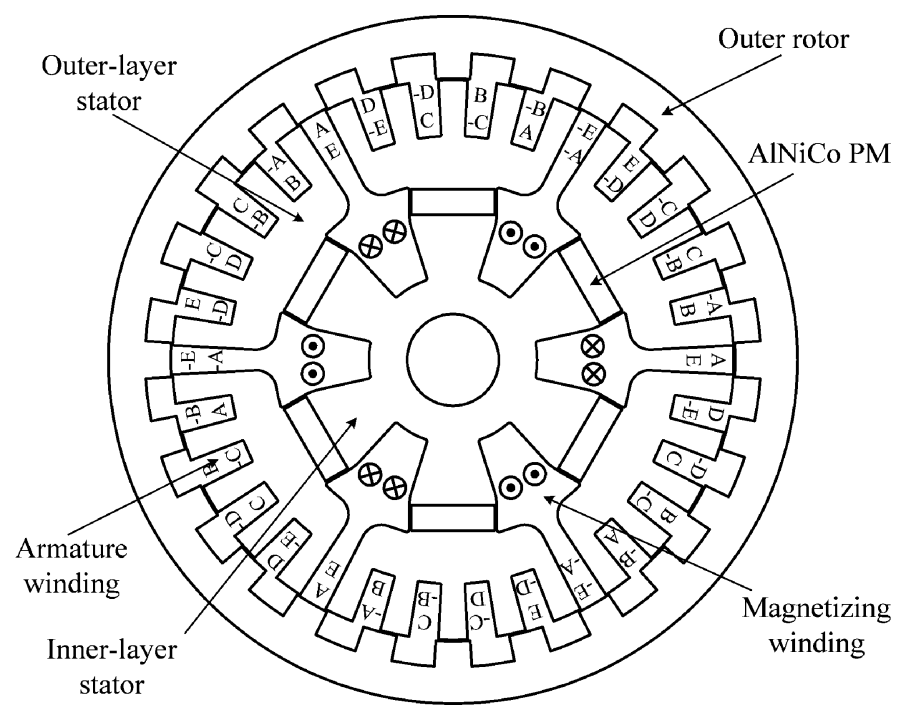

Fig. 1. Motor configuration.

operating conditions, and a high coercivity so as to avoid irreversible demagnetization under extreme operating conditions. Unfortunately, these two expectations were the shortcomings of AlNiCo PMs. Consequently, the AlNiCo PMs were superseded by the samarium-cobalt ( $\mathrm{SmCo}$ ) and neodymium-iron-boron (NdFeB) PMs for application to PM motors.

Dramatically, the aforementioned shortcomings of AlNiCo PMs are positively utilized in the memory motors. First, the nonlinearity of their demagnetization characteristics makes the recoil line never superpose on the demagnetization curve. Thus, once the demagnetization current is applied and then removed, the operating point will move along the recoil line and settle at a lower magnetization level, which means that the magnetization level is memorized. Second, the low coercivity is a desired feature to enable online demagnetization. This uniqueness cannot be provided by other PM materials, such as the SmCo or NdFeB PMs. Additionally, with both high thermal stability and high chemical stability, the AlNiCo PMs are the natural choice for the memory motors.

\section{B. Motor Configuration}

The configuration of the proposed memory motor is shown in Fig. 1, which adopts a five-phase outer-rotor 30/24-pole doubly salient structure. Its unique features are summarized in the following.

1) The use of five phases rather than three phases is to enhance the torque smoothness and to provide the capability of fault tolerance. These two features are particularly desirable for electric vehicles [14]. Also, a higher number of phases can offer better starting performance.

2) The use of outer rotor rather than the inner rotor is to provide the direct-drive capability for electric vehicles. Also, the inner space of the stator can be fully utilized to accommodate the PMs, armature windings, and magnetizing windings, hence, achieving a compact structure.
3) Since the armature windings and PMs are located in different layers of the stator, the PMs can be immune from accidental demagnetization by armature reaction. Also, the armature adopts fractional-slot windings with the coil span equal to the slot pitch; it not only reduces the cogging torque, but also shortens the end winding.

4) Similar to that of the switched reluctance (SR) or DSPM motors, the rotor is simply composed of salient poles with no PMs or windings. Thus, it is very robust.

5) Different from the dc field winding of the HF-DSPM motor, the magnetizing winding does not need to handle continual current flow or high power dissipation. Therefore, the corresponding size is small.

Because of the nature of doubly salient structure, the relationship among the stator pole number $N_{s}$, rotor pole number $N_{r}$, and phase number $m$ of the proposed dc-excited memory motor is similar to that of the SR or DSPM motor. It is governed by [15]

$$
\left\{\begin{array}{l}
N_{s}=2 m k \\
N_{r}=N_{s} \pm 2 k
\end{array}\right.
$$

where $k$ is a positive integer. According to (1), $m=5$ deduces $N_{\mathrm{s}}=10 k$ and $N_{\mathrm{r}}=8 k\left(N_{r}\right.$ is always smaller than $N_{s}$ in design). The use of more rotor poles, namely larger value of $N_{r}$, can generate more torque pulses per revolution, leading to have a smoother resultant torque. On the other hand, since the operating frequency is proportional to $N_{r}$, it should be limited to avoid causing high core losses. As a compromise, $k=3$ is chosen, hence, resulting in $N_{s}=30$ and $N_{r}=24$.

\section{Operation Principle}

The variation of air-gap flux of the proposed memory motor is induced by the permeance variation, not by the magnet rotation. Thus, the flux always tends to flow through the shortest path that the stator poles align with the rotor poles from the unaligned position, hence causing the motor rotation. Such operation principle is similar to that of the DSPM motor [7], except that the flux is controllable in the proposed motor.

The flux linkage per phase $\Psi$ is composed of the PM flux linkage $\Psi_{\mathrm{PM}}$ and the armature reaction flux linkage $\mathrm{Li}$

$$
\Psi=\Psi_{\mathrm{PM}}+L i .
$$

Neglecting the copper losses, the magnetic field coenergy $W^{\prime}$ can be obtained by subtracting the energy stored in the armature winding from the total input energy

$$
W^{\prime}=i \Psi-\frac{1}{2} L i^{2}=i \Psi_{\mathrm{PM}}+\frac{1}{2} L i^{2} .
$$

Therefore, the electromagnetic torque per phase $T_{e}$ can be deduced by differentiating the coenergy

$$
\begin{aligned}
T_{e} & =\frac{d}{d \theta_{m}}\left(i \Psi_{\mathrm{PM}}+\frac{1}{2} L i^{2}\right)=i \frac{d \Psi_{\mathrm{PM}}}{d \theta_{m}}+\frac{1}{2} i^{2} \frac{d L}{d \theta_{m}} \\
& =T_{\mathrm{PM}}+T_{r}
\end{aligned}
$$

where $L$ is the self-inductance, $i$ is the armature current per phase, $\theta_{m}$ is the mechanical rotor position, $T_{\mathrm{PM}}$ is the $\mathrm{PM}$ torque 


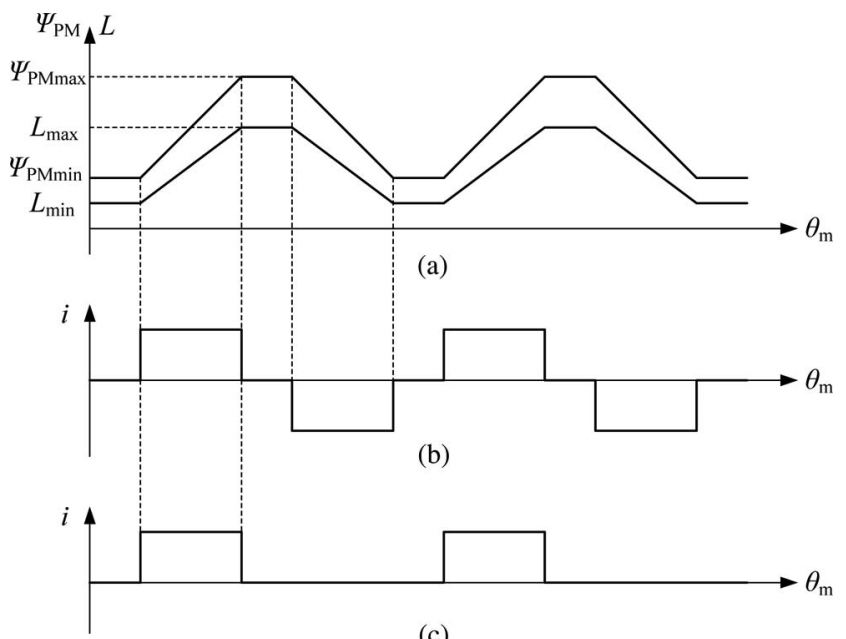

(c)

Fig. 2. Operation waveforms. (a) PM flux linkage and self-inductance. (b) Armature current at DSPM mode. (c) Armature current at SR mode.

component, which is due to the interaction between the armature current and PM flux linkage, and $T_{r}$ is the reluctance torque component, which is due to the variation of self-inductance. The theoretical waveforms of $\Psi_{\mathrm{PM}}$ and $L$ are shown in Fig. 2(a).

In order to make a unidirectional torque all the time, there are two operation modes. First, as shown in Fig. 2(b), a bipolar armature current is used, in which a positive current is applied when the flux linkage increases, whereas a negative current is applied when the flux linkage decreases. As a result, the PM torque becomes the dominant torque component, while the reluctance one is a parasitic pulsating torque with zero average value. This mode of operation is adopted in the DSPM motor, so-called the DSPM mode of the proposed motor. Second, as shown in Fig. 2(c), a unipolar armature current is used, in which only the positive current is applied in the period of increasing flux linkage and inductance. Since the period with decreasing flux linkage and inductance is not utilized, the torque density is sacrificed. This mode of operation is adopted in the SR motor, so-called the SR mode of the proposed motor.

Different from the DSPM and SR motors, the proposed memory motor has the uniqueness that it can operate in the DSPM mode when the PMs are fully magnetized, whereas operate in the SR mode when the PMs are fully demagnetized. Additionally, when the PMs are partially magnetized, it can select to operate in either the DSPM mode or SR mode, depending on the amplitude of flux linkage variation and the amplitude of inductance variation.

\section{MOTOR ANALYSIS}

\section{A. Hysteresis Model}

The practical $B$-- $H$ curve of AlNiCo PM material (Grade: AlNiCo 5DG) used in the proposed motor is plotted in Fig. 3, in which the remanence is $1.3 \mathrm{~T}$ and the coercivity is $56 \mathrm{kA} / \mathrm{m}$. Meanwhile, the second quadrant of the practical $B-H$ curve of a common NdFeB PM material (Grade: N35) is also plotted, in which the remanence is $1.2 \mathrm{~T}$ and the coercivity is $860 \mathrm{kA} / \mathrm{m}$. It

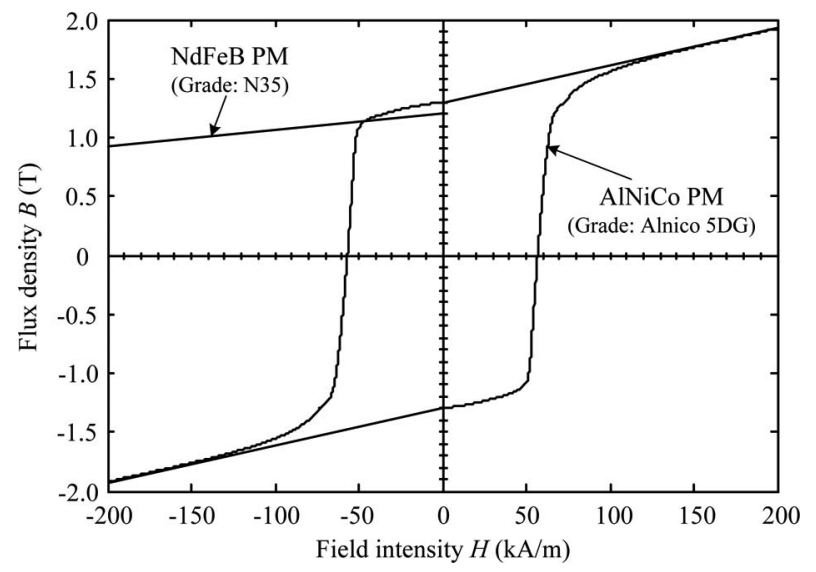

Fig. 3. $B-H$ curves of PM materials.

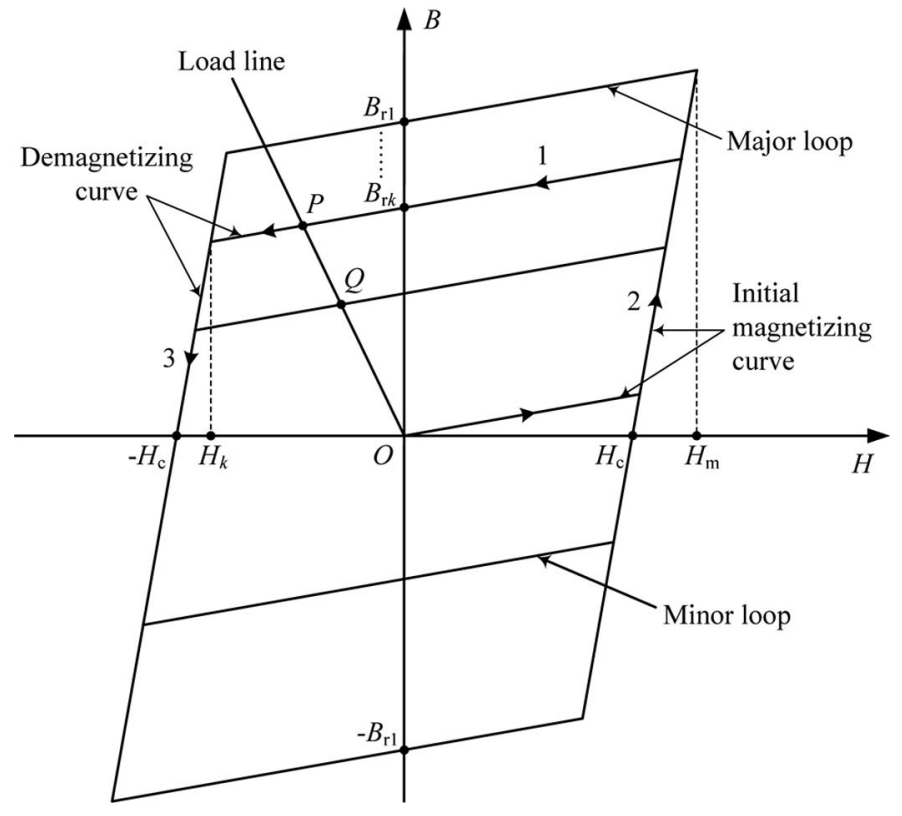

Fig. 4. Hysteresis model.

can be seen that the AlNiCo PM exhibits a nonlinear demagnetization characteristic and has a rather narrow $B--H$ loop with a knee in the second quadrant, which is different from that of the NdFeB PM.

Based on the actual hysteresis model expounded in [16], a piecewise-linear hysteresis model is proposed, as illustrated in Fig. 4, where the major hysteresis loop and all the minor hysteresis loops have the same value of coercivity $H_{c}$, but with different values of remanence $B_{r k}$, and the initial magnetizing curve partly superposes on the hysteresis loop. The relative permeability $\mu_{r}$ and recoil permeability $\mu_{\text {rec }}$ are the same.

As shown in Fig. 4, the main beelines that represent the magnetizing and demagnetizing processes are labeled with 1,2, and 3. During the magnetizing process, the operating point of the AlNiCo PM moves upward along the line 2, then leftward along the line 1 , and settles at the operating point $P$. Consequently, in the demagnetizing process, the operating point moves leftward along the line 1 , then downward along the line 3 , then rightward 
along the recoil line until settling at the operating point $Q$ with a lower flux level. The corresponding equations of these beelines can be, respectively, expressed as follows:

$$
\begin{aligned}
& B=\mu_{r} \mu_{0} H+B_{r k}, \quad k=1,2,3 \ldots, \\
& B=\frac{\mu_{r} \mu_{0} H_{m}+B_{r 1}}{H_{m}-H_{c}}\left(H-H_{c}\right) \\
& B=\frac{\mu_{r} \mu_{0} H_{m}+B_{r 1}}{H_{m}-H_{c}}\left(H+H_{c}\right)
\end{aligned}
$$

where $\mu_{0}$ is the vacuum permeability, $H_{m}$ is the saturated magnetic field intensity, and $B_{r k}$ denotes the remanence of $k$ th hysteresis loop. By using (5) and (7), the $H$ value of knee point of $k$ th loop in the second quadrant can be obtained as follows:

$$
\begin{array}{r}
H_{k}=\frac{\left(H_{m}-H_{c}\right) B_{r k}-H_{c}\left(\mu_{r} \mu_{0} H_{m}+B_{r 1}\right)}{\mu_{r} \mu_{0} H_{c}+B_{r 1}}, \\
k=1,2,3 \ldots
\end{array}
$$

First, in the initial magnetizing state, a temporary positive magnetizing force $H$ is applied. The corresponding remanence of each PM element can be expressed as follows:

$$
B_{r}=\left\{\begin{array}{lr}
0 & 0 \leq H \leq H_{c} \\
\frac{\mu_{r} \mu_{0} H_{m}+B_{r 1}}{H_{m}-H_{c}}\left(H-H_{c}\right)-\mu_{r} \mu_{0} & H H_{c}<H<H_{m} \\
B_{r 1} & H_{m} \leq H .
\end{array}\right.
$$

Second, in the working state, the $B$ value of each PM element is calculated from (5) according to its associated $B_{r k}$ and the currently applied negative magnetizing force $H$. At each time step, the value of $B_{r k}$ is modified until it converges using the underrelax iteration method, which is given by

$$
B_{r}=\left\{\begin{array}{lc}
B_{r k} & H_{k} \leq H \leq 0 \\
\frac{\mu_{r} \mu_{0} H_{m}+B_{r 1}}{H_{m}-H_{c}}\left(H+H_{c}\right)-\mu_{r} \mu_{0} H-H_{c}<H<H_{k} \\
\mu_{r} \mu_{0}\left[H+H_{c}-\frac{\left(\mu_{r} \mu_{0} H+B_{r k}\right)\left(H_{m}-H_{c}\right)}{\mu_{r} \mu_{0} H+B_{r 1}}\right] \\
+B_{r k} \quad H \leq-H_{c} .
\end{array}\right.
$$

\section{B. Finite-Element Analysis}

The time-stepping FEM (TS-FEM) is a well-accepted numerical tool to analyze PM motors [17]. By incorporating the aforementioned hysteresis model into the TS-FEM, both steady-state and transient performances of the proposed dc-excited memory motor can be analyzed.

First, by temporarily tuning the magnetizing current, the PM magnetization level can be flexibly adjusted from the full level by using a magnetizing magnetomotive force (MMF) of 2500 A-turn, then the half level by using a demagnetizing MMF of 375 A-turn, and consequently the weak level by using a demagnetizing MMF of 500 A-turn. The corresponding magnetic field distributions at no load are shown in Fig. 5(a)-(c). It can be observed that the magnetic flux lines can be tuned by simply using temporary magnetization and demagnetization. In order to verify the immunity of the AlNiCo PMs from accidental

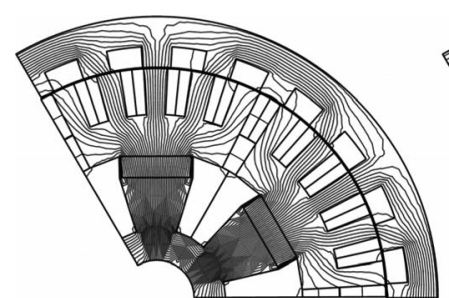

(a)

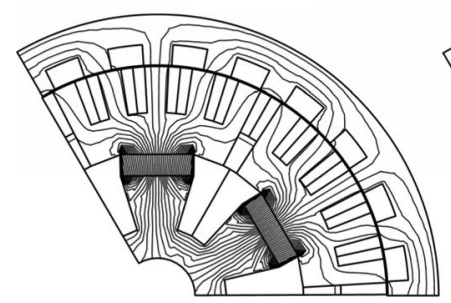

(c)

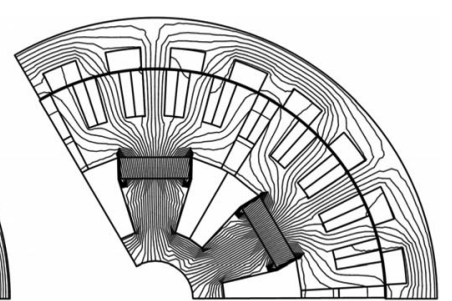

(b)

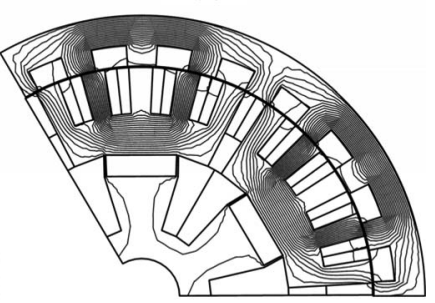

(d)
Fig. 5. Magnetic field distributions. (a) No load at full level magnetization. (b) No load at half level magnetization. (c) No load at weak level magnetization. (d) Full-load armature currents at no magnetization.

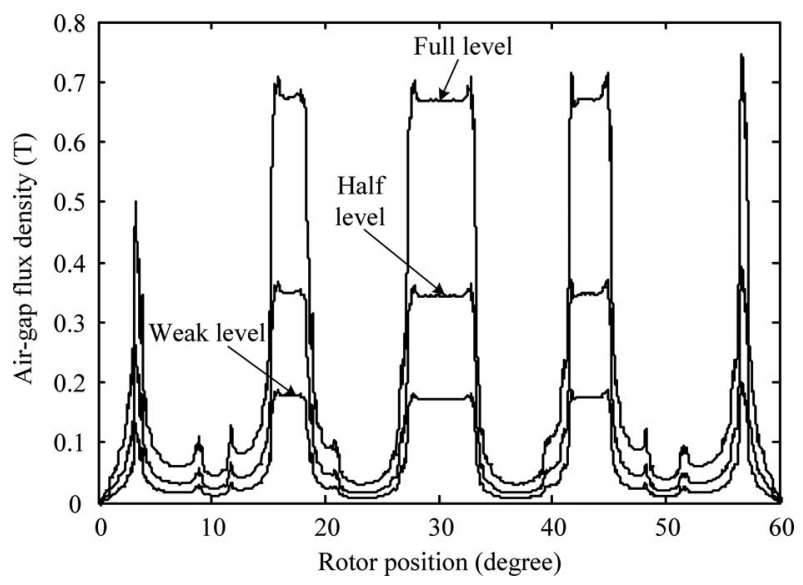

Fig. 6. Air-gap flux density distributions at different PM magnetization levels.

demagnetization by armature reaction, the magnetic field distribution is further analyzed under the conditions that the armature winding currents are at full load and the PMs have been purposely fully demagnetized. As shown in Fig. 5(d), the armature reaction field concentrates on the outer-layer stator only, thus, avoiding accidental demagnetization of the PMs. Moreover, the corresponding air-gap flux density distributions at no load are depicted in Fig. 6. It can be found that the air-gap flux density can be controlled over a wide range, up to about four times.

Second, Fig. 7 shows the PM flux linkage of phase-A under the full magnetization level, as well as the self and mutual inductances of phase-A under the rated armature current of $5 \mathrm{~A}$. It can be seen that the mutual inductances are much smaller than the self-inductance due to the concentrated armature winding. Additionally, the self-inductance characteristics with respect to both rotor position and armature current are shown in Fig. 8. It indicates that the self-inductance is not only position dependent, but also current dependent.

Third, the back-EMF waveforms of the proposed memory motor at the speed of $200 \mathrm{r} / \mathrm{min}$ under different PM magneti- 


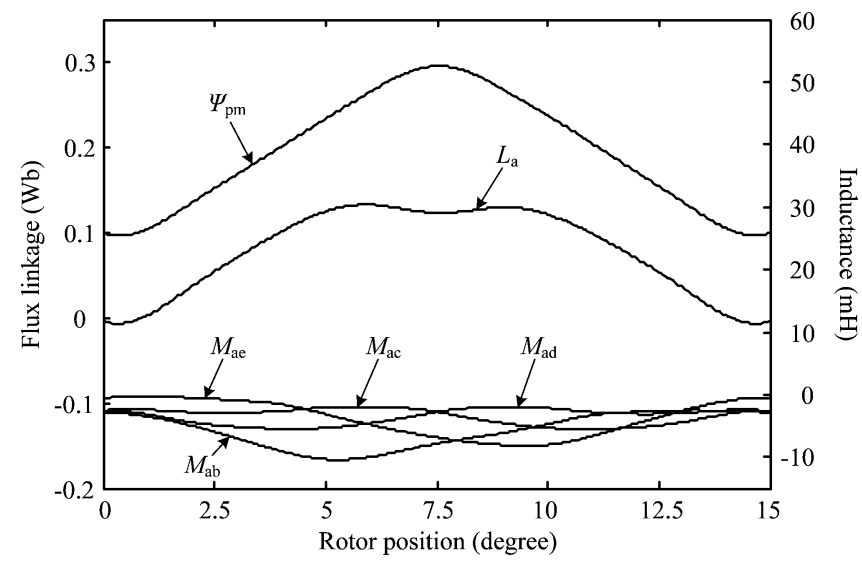

Fig. 7. PM flux linkage and inductances.

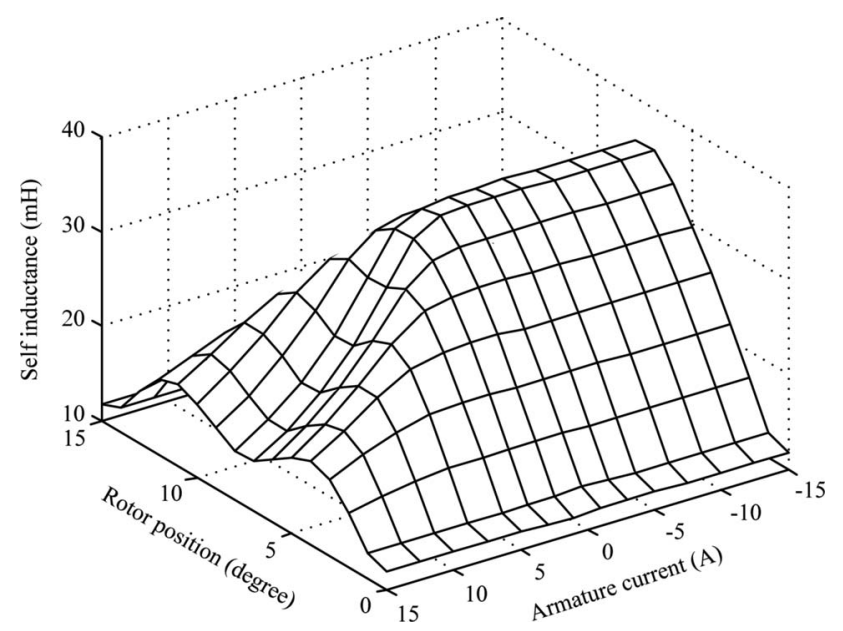

Fig. 8. Self-inductance characteristics.

zation levels are simulated, as shown in Fig. 9. As expected, the amplitude can be effectively controlled for about four times, which agrees well with the controllable range of air-gap flux. Similar to the DSPM or SR motors [18], the proposed memory motor adopts the current chopping control for normal operation. Fig. 10 shows the corresponding armature current waveform at the speed of $200 \mathrm{r} / \mathrm{min}$.

Fourth, the transient performances of the proposed memory motor are simulated. Fig. 11 shows the simulated back-EMF response at the speed of $100 \mathrm{r} / \mathrm{min}$ subjected to a temporary demagnetizing current of $1.5 \mathrm{~A}$. It can be found that the back-EMF can be swiftly reduced, while the duration of demagnetizing current needs only about $0.1 \mathrm{~s}$. Moreover, the transient responses of the motor speed and torque during starting and then under flux-weakening are simulated, as shown in Fig. 12. Initially, the motor is started at the rated condition with the full-load torque of $15 \mathrm{Nm}$ until reaching the steady-state speed of $600 \mathrm{r} / \mathrm{min}$. Then, a demagnetizing current pulse is applied to weaken the air-gap flux to the half level of PM magnetization, while the load torque is halved. It can be observed that the rotor speed can swiftly rise up to the speed of $1200 \mathrm{r} / \mathrm{min}$, namely two times the rated speed, due to the flux-weakening action.

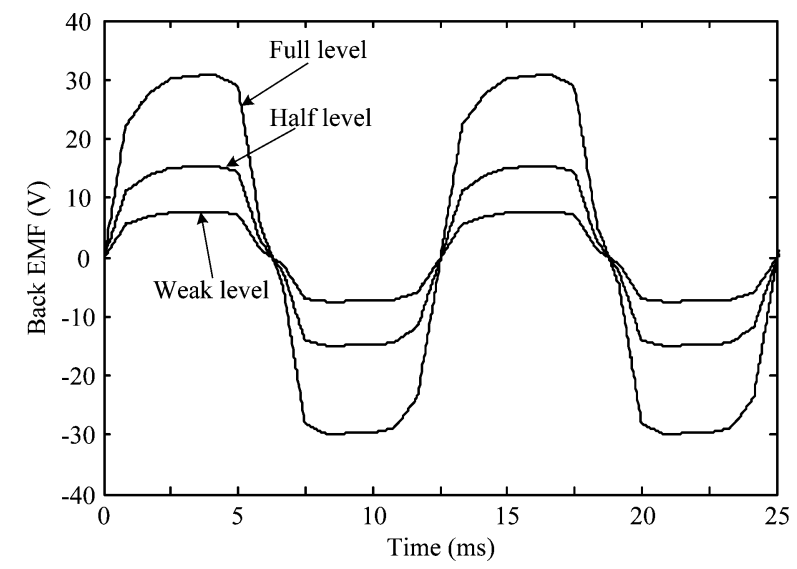

Fig. 9. Simulated back-EMF waveforms at $200 \mathrm{r} / \mathrm{min}$ under different $\mathrm{PM}$ magnetization levels.

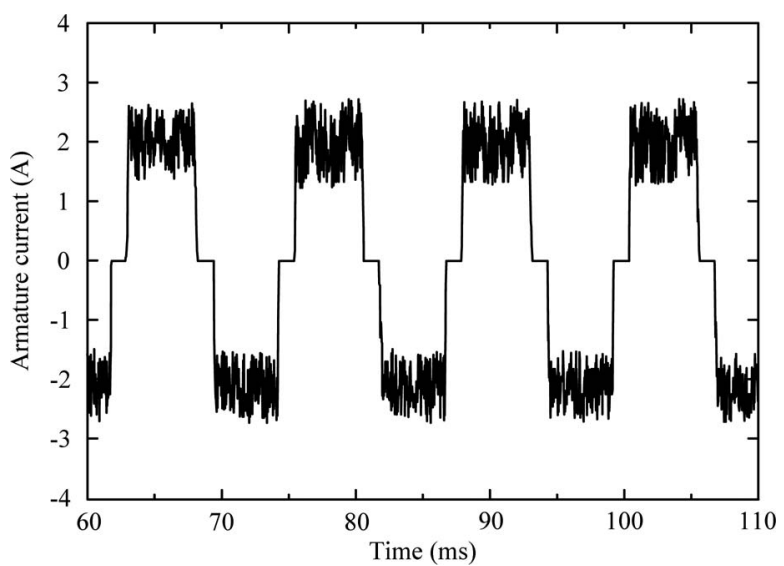

Fig. 10. Simulated armature current waveform at $200 \mathrm{r} / \mathrm{min}$.

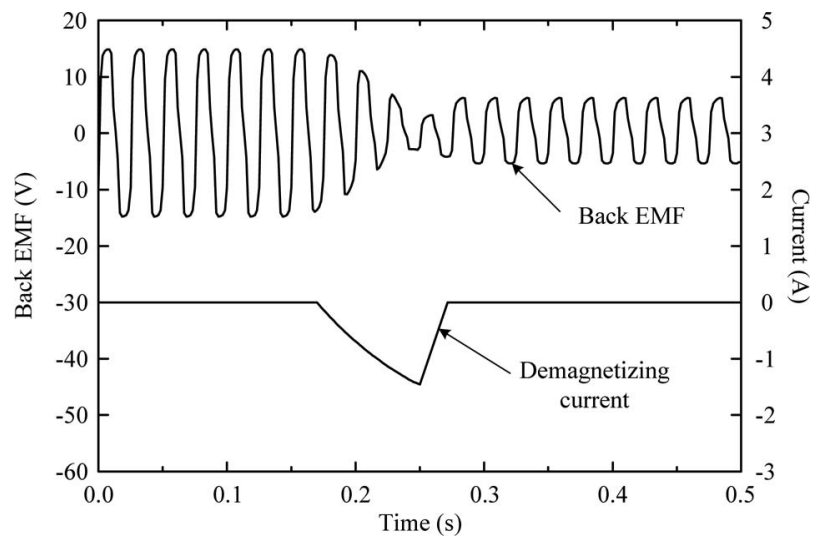

Fig. 11. Simulated back-EMF and demagnetizing current responses under short duration of demagnetizing current.

\section{Comparison With HF-DSPM Motor}

In order to provide a quantitative comparison, an HF-DSPM motor using $\mathrm{NdFeB} \mathrm{PMs} \mathrm{is} \mathrm{designed} \mathrm{with} \mathrm{the} \mathrm{same} \mathrm{machine}$ topology, same stator, and rotor dimensions, as well as same turns of armature and field windings, but only one-fifth PM 


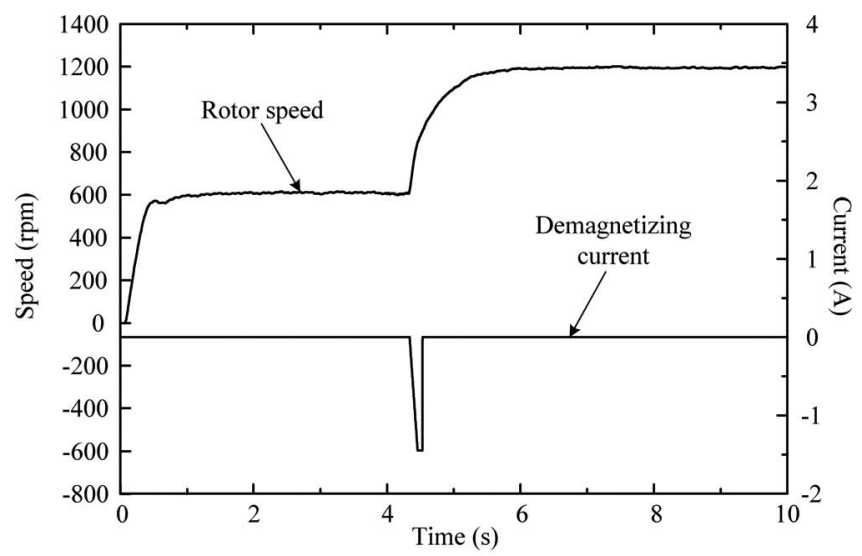

(a)

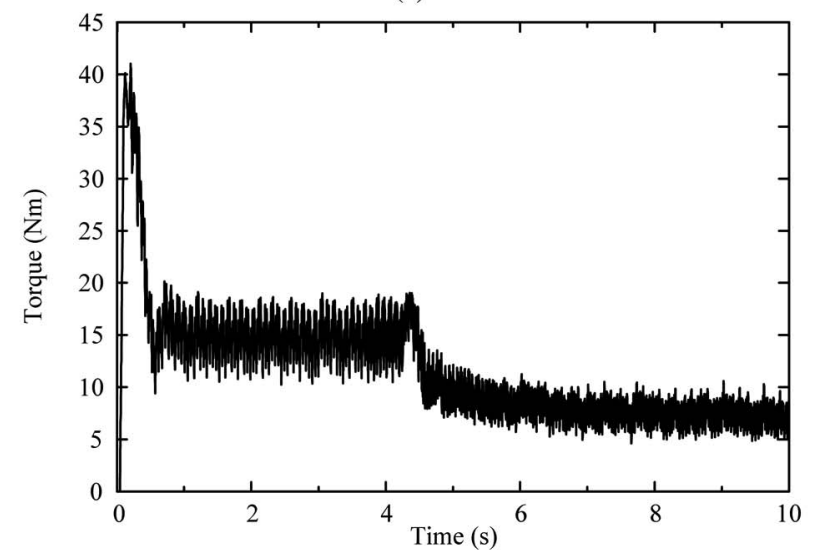

(b)

Fig. 12. Simulated transient responses under startup and flux-weakening. (a) Motor speed and demagnetizing current. (b) Motor torque.

thickness, as that of the proposed memory motor. As shown in Fig. 3, the energy products of AlNiCo PMs and NdFeB PMs are 52 and $280 \mathrm{~kJ} / \mathrm{m}^{3}$, respectively. Meanwhile, the densities of iron core, AlNiCo PM, and NdFeB PM are 7.8, 7.3, and $7.5 \mathrm{~g} / \mathrm{cm}^{3}$, respectively. Therefore, with the same electric loading and magnetic loading, their output powers, weights, and hence power densities can be estimated by using power equations [8]. As listed in Table I, the power density of the HF-DSPM motor is $24 \%$ higher than that of the proposed motor. The difference of their torque densities is similar to that of their power densities. However, the merit of this HF-DSPM motor is offset by the field winding copper loss. Quantitatively, the proposed memory motor has negligible magnetizing winding copper loss, whereas the HF-DSPM motor has field winding copper loss of 20.8 and $72.1 \mathrm{~W}$ during normal motoring operation and halflevel flux-weakening operation, respectively.

\section{MOTOR CONTROL}

\section{A. Speed Control}

As aforementioned, the proposed memory motor can operate at either the DSPM mode or SR mode, where bipolar or unipolar armature current is applied, respectively. For the normal case that the PMs are not fully demagnetized, the DSPM mode of
TABLE I

COMPARISON BETWEEN PROPOSED MOTOR AND HF-DSPM MOTOR

\begin{tabular}{lcc}
\hline \hline & Proposed motor & HF-DSPM motor \\
\hline Rated power & $942 \mathrm{~W}$ & $1175 \mathrm{~W}$ \\
PM size & $26.4 \mathrm{~cm}^{3}$ & $5.3 \mathrm{~cm}^{3}$ \\
Weight & $29.9 \mathrm{~kg}$ & $30.0 \mathrm{~kg}$ \\
Power density & $31.5 \mathrm{~W} / \mathrm{kg}$ & $39.2 \mathrm{~W} / \mathrm{kg}$ \\
Field copper loss & Negligible & $20.8 \sim 72.1 \mathrm{~W}$ \\
\hline \hline
\end{tabular}

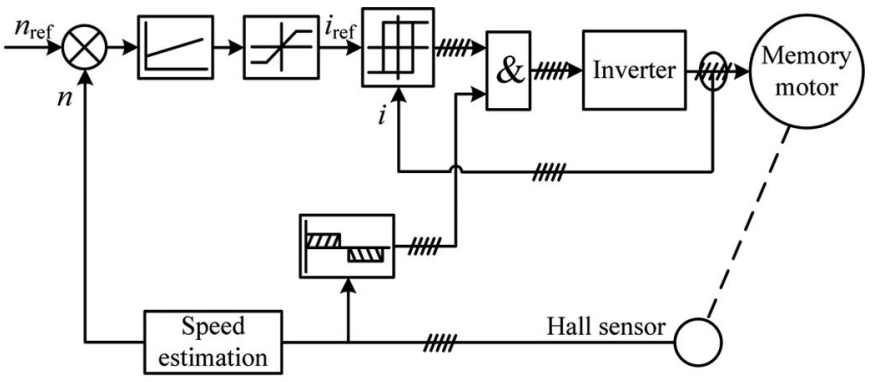

(a)

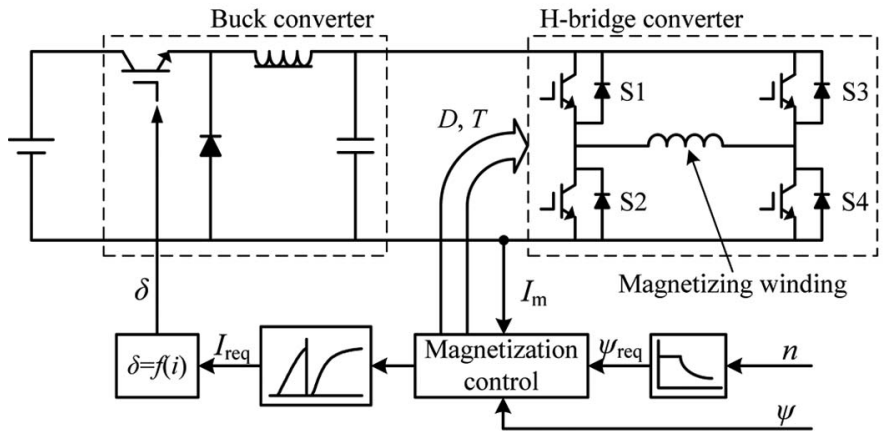

(b)

Fig. 13. Proposed control strategies. (a) Speed control. (b) Flux control.

operation is adopted. Fig. 13(a) shows the corresponding speed control block diagram, in which there are two feedback loops, namely the inner current loop with a hysteresis band regulator and the outer speed loop with a proportional-integral (PI) regulator. Then, with the aid of Hall position sensors, the conduction signal of each phase is combined with the associated hysteresis regulator signal, hence forming the firing signal of each power device.

The relationships among the back-EMFs, Hall signals, and conduction signals of all phases are depicted in Fig. 14. The back-EMFs are trapezoidal waveforms. The corresponding Hall signals are adjusted in such a way that they align with the maximum values of the back-EMFs. Hence, the power devices in the upper or lower leg of each phase of the inverter are conducted at the rising or falling edge of the relevant Hall signal, respectively. At any instant, there are four phase windings in the conducting state, while one phase winding in the commutating state. Each phase winding conducts $144^{\circ}$, while the phase shift between any two adjacent phases is $72^{\circ}$. 
(a)

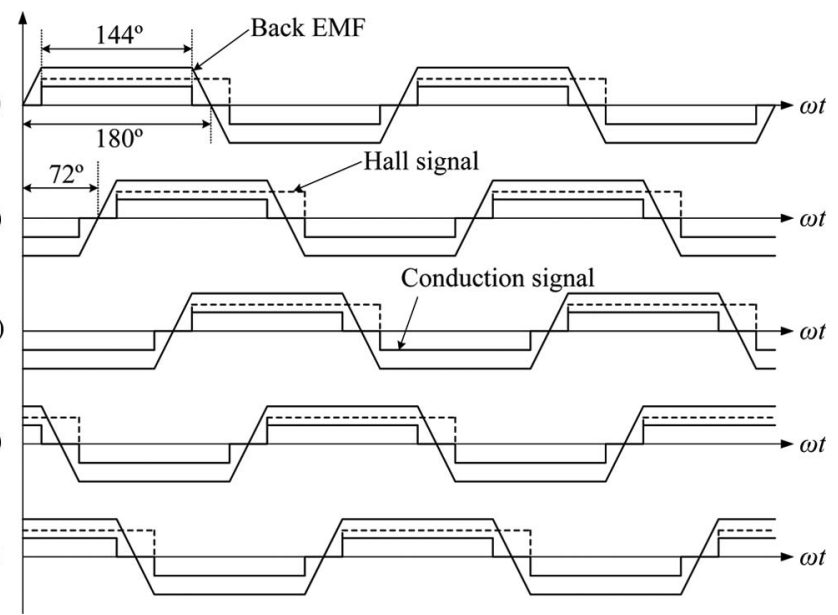

Fig. 14. Waveforms of back-EMFs, Hall signals, and conduction signals.

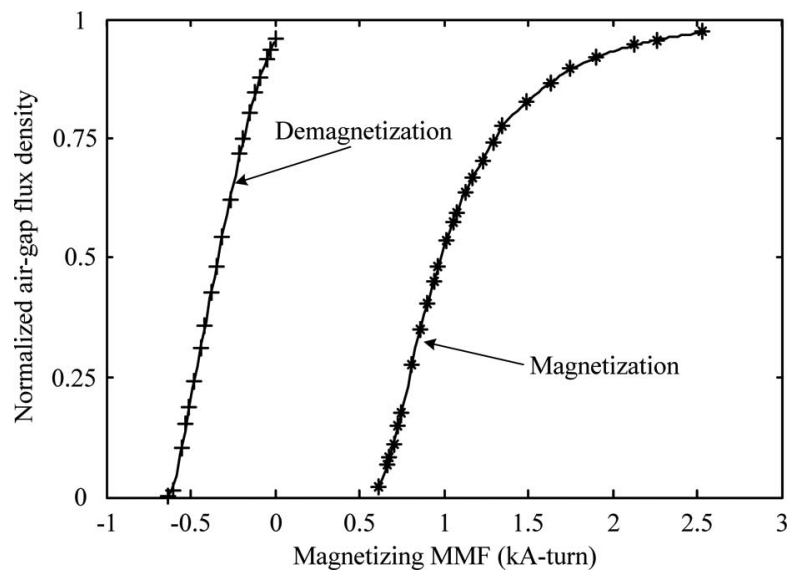

Fig. 15. Relationship between air-gap flux density and magnetizing MMF.

\section{B. Flux Control}

The flux controller of the proposed memory motor is different from the conventional one, since it needs to produce a temporary current pulse, controllable in both magnitude and direction. As illustrated in Fig. 13(b), the power stage consists of a buck converter and an H-bridge converter, where the former functions to control the magnitude $I_{m}$ of the magnetizing current and the latter serves to control the direction $D$ and duration $T$ of the magnetizing current. For instance, under flux-weakening operation, the required air-gap flux $\Psi_{\text {req }}$ deduced from the motor speed $n$ is compared with the estimated $\Psi$ from the flux observer, hence, $D$ will be easily determined. The value of $T$ is simply the minimum duration to accomplish the demagnetization or magnetization process, which does not need to be controlled. Consequently, the required magnitude of demagnetizing or magnetizing current $I_{\text {req }}$ is deduced from the relationship between air-gap flux density and magnetizing MMF. This relationship can be obtained by using FEM, as shown in Fig. 15, in which the air-gap flux density is normalized by its full level of PM magnetization. Finally, the duty cycle $\delta$ of the buck converter is adjusted to tune its output voltage, and hence the value of $I_{m}$.

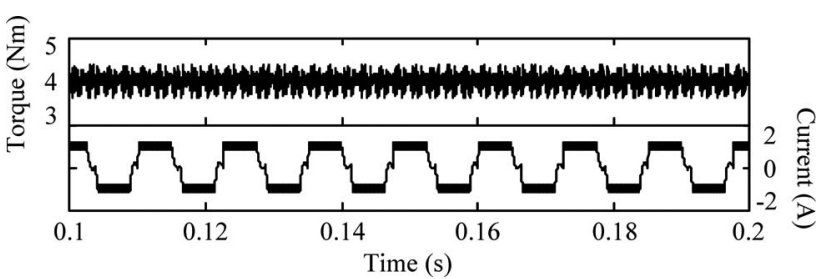

(a)

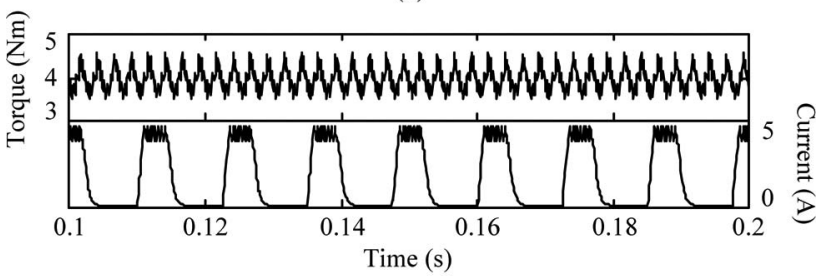

(b)

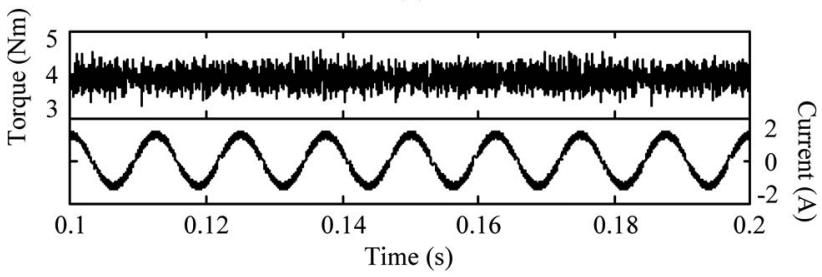

(c)

Fig. 16. Simulated output torque and armature current waveforms under different control methods. (a) BLDC control. (b) SR control. (c) BLAC control.

TABLE II

KEY DESIGN DATA

\begin{tabular}{ll}
\hline \hline Rated power & $942 \mathrm{~W}$ \\
Rated torque & $15 \mathrm{Nm}$ \\
Rated speed & $600 \mathrm{r} / \mathrm{min}$ \\
Speed range & $0 \sim 2000 \mathrm{r} / \mathrm{min}$ \\
Stator outside diameter & $220.0 \mathrm{~mm}$ \\
Rotor inside diameter & $221.2 \mathrm{~mm}$ \\
Rotor outside diameter & $270.0 \mathrm{~mm}$ \\
Stack length & $80.0 \mathrm{~mm}$ \\
No. of turns per armature coil & 60 \\
No. of turns per magnetizing coil & 250 \\
Rotor pole arc & $7 \mathrm{degree}$ \\
Stator pole arc & $6 \mathrm{degree}$ \\
PM material & Alnico $5 \mathrm{DG}$ \\
PM dimensions (width $\times$ thickness) & $33 \times 10 \mathrm{~mm}$ \\
PM remanent flux density & $1.3 \mathrm{~T}$ \\
PM coercive force & $56 \mathrm{kA} / \mathrm{m}$ \\
\hline \hline
\end{tabular}

\section{Comparison of Control Methods}

The proposed memory motor normally operates with the aforementioned DSPM control method, which is essentially the conventional brushless dc (BLDC) one using bipolar rectangular armature current. Also, it can adopt the SR control method using unipolar rectangular armature current, and the brushless ac (BLAC) control method using bipolar sinusoidal armature current. Fig. 16 shows a comparison of their simulated armature current and output torque waveforms. It can be found that the motor can offer the minimum torque ripple under the DSPM control method, hence confirming that it is the most appropriate control method for the motor. 


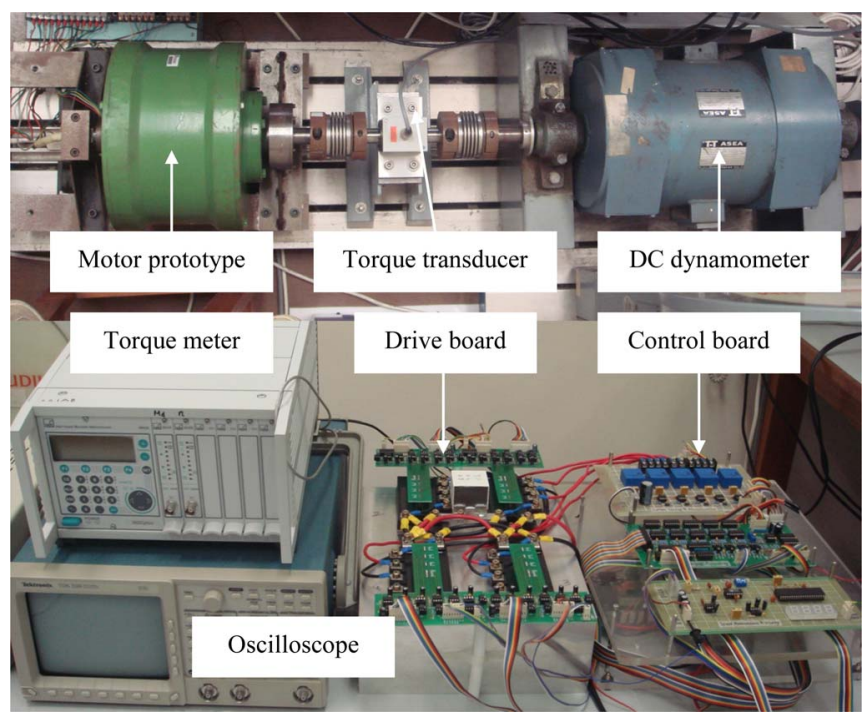

Fig. 17. Experimental setup.

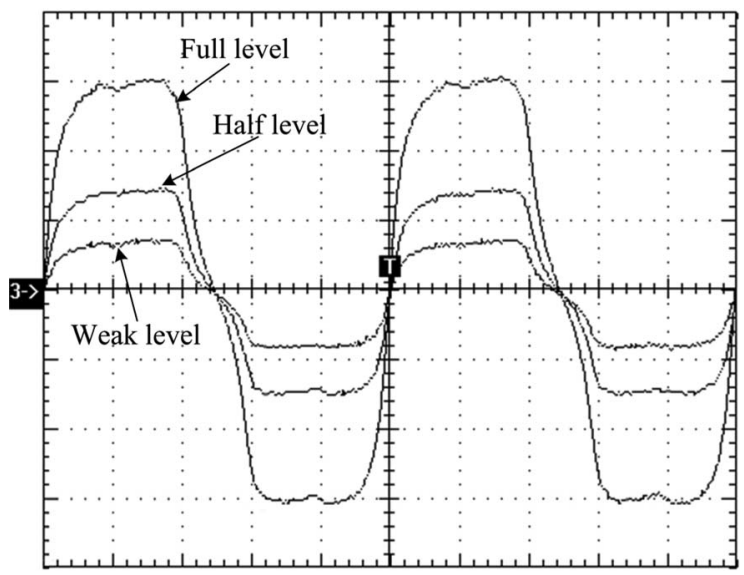

Fig. 18. Measured back-EMF waveforms at $200 \mathrm{r} / \mathrm{min}$ under different PM magnetization levels ( $10 \mathrm{~V} / \mathrm{div}, 2.5 \mathrm{~ms} / \mathrm{div})$.

\section{EXPERIMENTAL VERIFICATION}

A prototype of the proposed dc-excited memory motor is built for experimental verification. The key design data are listed in Table II. This motor prototype is coupled with a dc dynamometer via a dynamic torque transducer (range: $0-100 \mathrm{Nm}$ ), and then mounted onto the test bed. A five-phase inverter and an H-bridge circuit are designed and built to drive the armature winding and magnetizing winding of the motor, respectively. All the control algorithms are implemented in a Texas Instrument digital signal processor (DSP) microcontroller TMS320F240 (CPU clock frequency: $20 \mathrm{MHz}$ ). The implementation setup is shown in Fig. 17.

First, the steady-state characteristics of the proposed memory motor are experimented. The back-EMF waveforms at the speed of $200 \mathrm{r} / \mathrm{min}$ under the full level, half level, and weak level of PM magnetization are measured, as shown in Fig. 18. It can be found that the measured waveforms well agree with the simulated results under the same operating conditions, as shown in Fig. 9. Then, the armature current waveforms of two

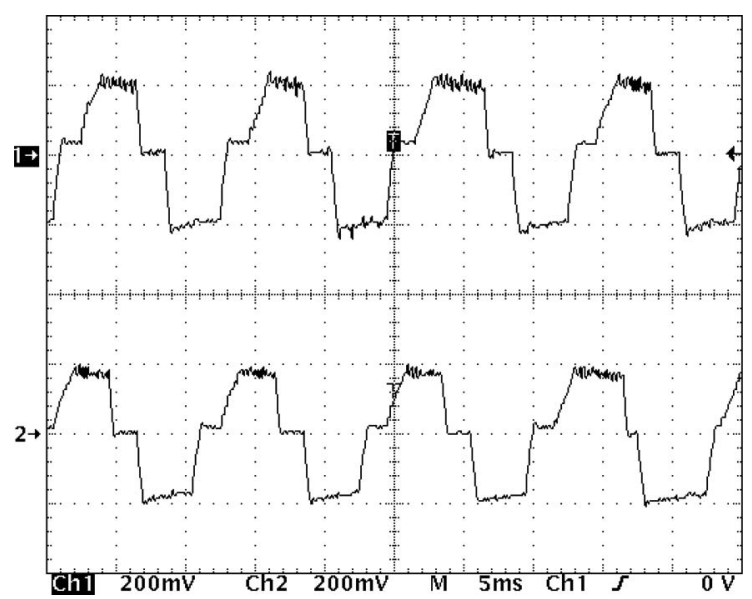

Fig. 19. Measured armature current waveforms of two adjacent phases at $200 \mathrm{r} / \mathrm{min}(2 \mathrm{~A} / \mathrm{div}, 2 \mathrm{~A} / \mathrm{div}, 5 \mathrm{~ms} / \mathrm{div})$.

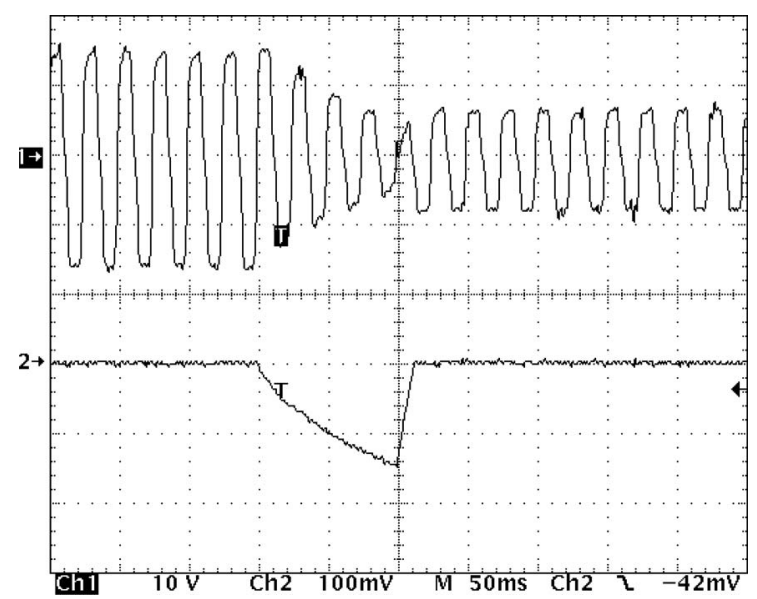

Fig. 20. Measured back-EMF and demagnetizing current responses under short duration of demagnetizing current (10 V/div, $1 \mathrm{~A} / \mathrm{div}, 50 \mathrm{~ms} / \mathrm{div})$.

adjacent phases (namely, the phase-A and phase-B) at the speed of $200 \mathrm{r} / \mathrm{min}$ are measured, as shown in Fig. 19. As expected, they closely match with the simulated one, as shown in Fig. 10. The measured waveforms also verify that the phase shift of the proposed motor is $72^{\circ}$.

Second, the transient response of the back-EMF at the speed of $100 \mathrm{r} / \mathrm{min}$ subjected to a temporary demagnetizing current is measured, as shown in Fig. 20. Namely, by applying a demagnetizing current of about $1.5 \mathrm{~A}$ with a duration of about $0.1 \mathrm{~s}$, the back-EMF can be swiftly reduced. As compared with the simulated response under the same operating conditions, as shown in Fig. 11, the agreement is very good, thus verifying the accuracy and validity of the proposed TS-FEM coupled with hysteresis model for analysis of the proposed memory motor.

Third, the transient performance of the proposed motor at constant power operation is assessed, as shown in Fig. 21. Namely, the motor initially operates at the rated speed of $600 \mathrm{r} / \mathrm{min}$ and rated load torque of $15 \mathrm{Nm}$. At the same time of reducing the load 


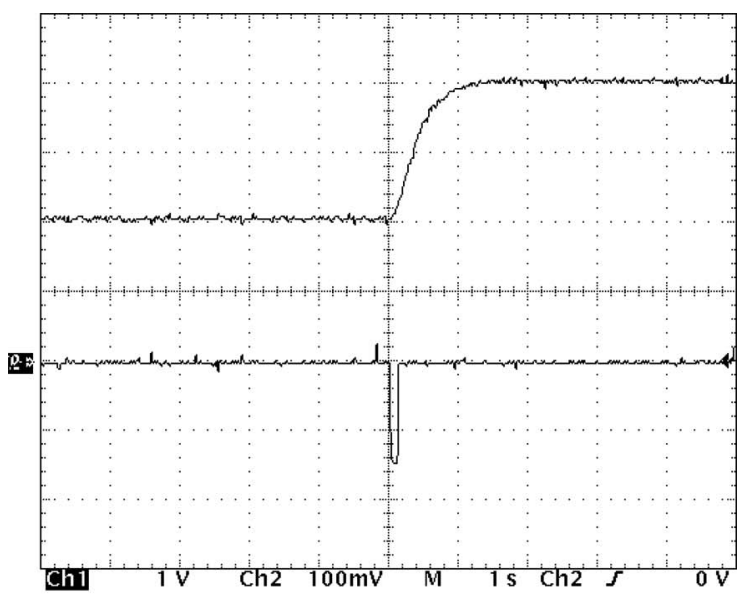

(a)

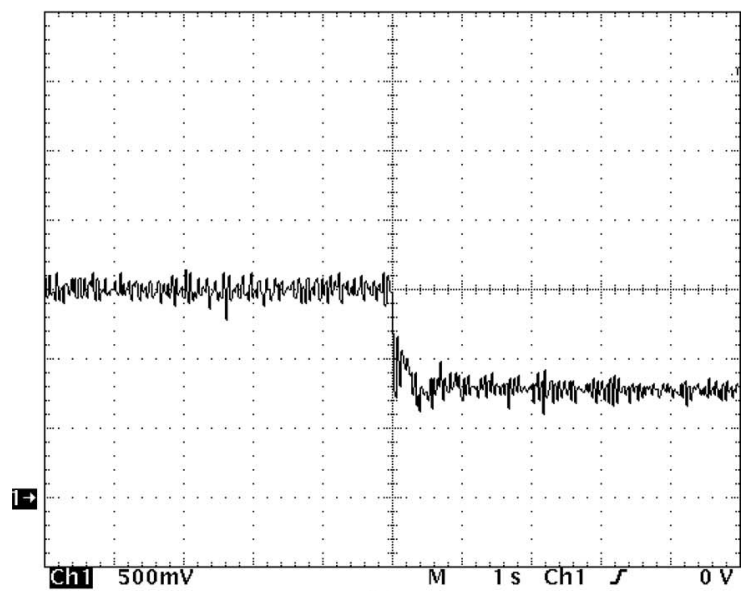

(b)

Fig. 21. Measured transient responses under flux-weakening. (a) Motor speed and demagnetizing current $(300 \mathrm{r} / \mathrm{min} / \mathrm{div}, 1 \mathrm{~A} / \mathrm{div}, 1 \mathrm{~s} / \mathrm{div})$. (b) Motor torque (5 Nm/div, $1 \mathrm{~s} /$ div $)$.

torque from 15 to $7.5 \mathrm{Nm}$, the air-gap flux is weakened by applying a temporary demagnetizing current pulse. It can be found that the motor can swiftly increase the speed from 600 to 1200 $\mathrm{r} / \mathrm{min}$. As compared with the simulated responses under fluxweakening, as shown in Fig. 12, the agreement is also very good.

Finally, the torque-speed capabilities of the proposed motor with and without flux control are measured and then plotted in Fig. 22, where $F_{\mathrm{mag}}$ is the demagnetizing MMF. It reveals that by online tuning the PM magnetization levels, the proposed memory motor can effectively extend the constant power operation region over a wide speed range. As illustrated in Fig. 22, without flux control, the motor speed can only reach $1080 \mathrm{r} / \mathrm{min}$ (1.8 times the base speed). With the use of flux control, the motor can provide constant-power operation up to $1800 \mathrm{r} / \mathrm{min}$ (three times the base speed). It can further extend the adjustable speed range well beyond $1800 \mathrm{r} / \mathrm{min}$, provided that the load torque is lower than the motor torque. Moreover, the startup transient speed response at no load is measured, as shown in Fig. 23. It reveals that the proposed motor has a fast low-speed response from standstill to $450 \mathrm{r} / \mathrm{min}$, only taking less than $1 \mathrm{~s}$ for startup.

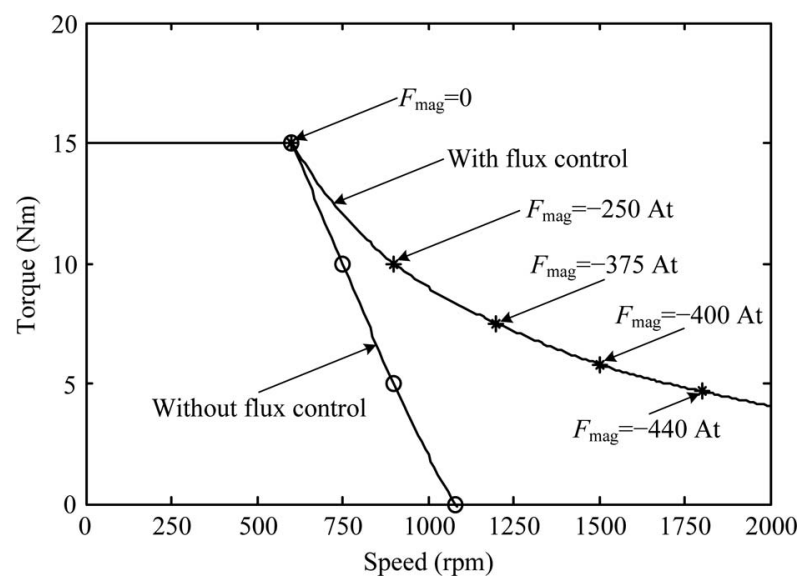

Fig. 22. Measured torque-speed capabilities with and without flux control.

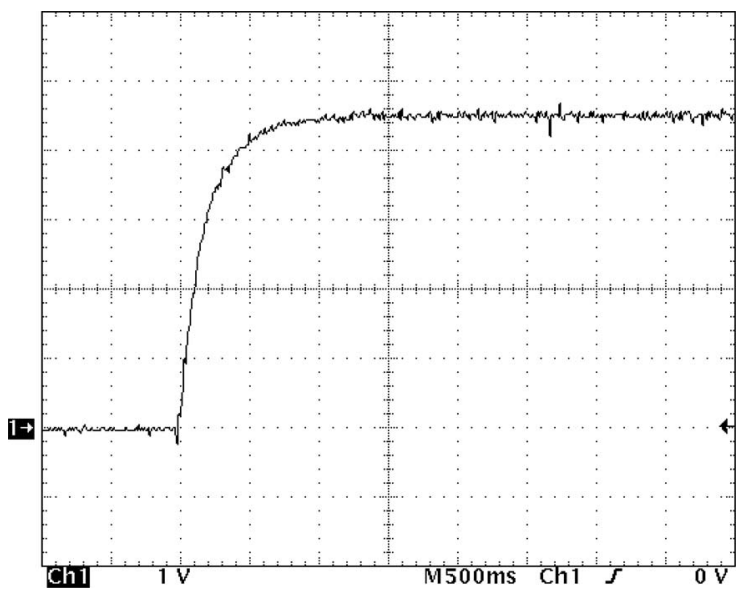

Fig. 23. Measured startup transient speed response at no load $(100 \mathrm{r} / \mathrm{min} / \mathrm{div}$, $500 \mathrm{~ms} / \mathrm{div})$.

\section{FURTHER DISCUSSIONS}

Compared with traditional DSPM motors, the HF-DSPM motor causes additional power loss during field excitation. It has been discussed in [19] that this field excitation loss can be partially compensated by the efficiency improvement due to air-gap flux control. Since the proposed motor has a similar structure as this HF-DSPM motor, but using temporary dc current pulse rather than continual dc current, the corresponding field excitation loss is almost eliminated. Therefore, the efficiency of the proposed motor is definitely higher than that of the hybrid-field one. Also, it should be similar to that of traditional DSPM motors for general applications, and even better for those applications desiring frequent changes of air-gap flux density such as electric vehicles. On the other hand, it has also been discussed in [19] that the HF-DSPM motor has a lower cost per unit power than the traditional DSPM motors because the whole motor cost is dictated by the required PM volume. Since the AlNiCo PM has a lower maximum energy product than the $\mathrm{NdFeB} \mathrm{PM,} \mathrm{but} \mathrm{with}$ a lower cost per unit volume, the proposed motor should have a similar cost per unit power as the hybrid-field one. 
In summary, the proposed motor has four key advantages.

1) Efficient flux control: the use of a temporary dc current pulse to perform air-gap flux control, instead of using continual dc excitation.

2) Effective flux control: the use of a small magnetizing winding to perform direct magnetization of PMs, thus eliminating complicated indirect current control.

3) High mechanical integrity: all windings and PMs are located in the stator while the rotor is simply iron core with salient poles.

4) Immunity from armature reaction: the location of armature windings and PMs are in different layers of the stator, hence enabling the PMs immune from accidental demagnetization by armature reaction.

Nevertheless, it has two key disadvantages: 1) lower power density: due to the utilization of AINiCo PM material and the need of additional magnetizing windings for online PM magnetization, the power density is inevitably lower than that of a traditional PM motor; and 2) more complicated structure: due to the use of two stator layers to accommodate both armature and magnetizing windings as well as PMs, the machine structure and hence manufacturing process are more complicated than a traditional PM motor.

The proposed dc-excited memory motor can perform effective air-gap flux control while involving negligible power loss as compared with other flux-controllable PM motors. This feature makes it promising for those applications requiring a wide range of air-gap flux control. A number of potential applications are identified: the traction motor for electric vehicles that desire a wide constant power motoring range for cruising [1]; the integrated starter-generator (ISG) for automobiles or hybrid electric vehicles that desire a high starting torque for cold cranking and a constant generated voltage over a wide speed range for battery charging [2]; the wind generator that desires a constant output voltage under varying and intermittent wind speeds [10]; and the aircraft generator that desires a nonfluctuating output voltage under various speeds and loads [20].

\section{CONCLUSION}

A new type of memory motor, namely the dc-excited memory motor, has been proposed and implemented. By uniquely integrating the AlNiCo PMs into a 30/24-pole outer-rotor doubly salient motor structure, the proposed memory motor offers effective and efficient air-gap flux control. This memory motor not only overcomes the drawbacks of its ac-excited counterpart, but also possesses the advantages of mechanical robustness, and wide-range constant power operation. Both simulation and experimentation have been carried out to confirm the accuracy of the analysis results and the validity of the proposed motor. Finally, some promising applications of this motor have been identified.

Like other DSPM motors, the proposed motor has salient poles in both the stator and rotor. Therefore, it should have the torque ripple and audible noise characteristics sim- ilar to that of DSPM motors [21]. Nevertheless, the effect of online PM magnetization on torque ripple and audible noise of the proposed motor is worthwhile for future investigation.

\section{REFERENCES}

[1] Z. Q. Zhu and D. Howe, "Electrical machines and drives for electric, hybrid and fuel cell vehicles," Proc. IEEE, vol. 95, no. 4, pp. 746-765, Apr. 2007.

[2] K. T. Chau, C. C. Chan, and C. Liu, "Overview of permanentmagnet brushless drives for electric and hybrid electric vehicles," IEEE Trans. Ind. Electron., vol. 55, no. 6, pp. 2246-2257, Jun. 2008.

[3] S. D. Sudhoff, K. A. Corzine, and H. J. Hegner, "A flux-weakening strategy for current-regulated surface-mounted permanent-magnet machine drives," IEEE Trans. Energy Convers., vol. 10, no. 3, pp. 431-437, Sep. 1995

[4] M. N. Uddin, T. S. Padwan, and M. A. Rahman, "Performance of interior permanent magnet motor drive over wide speed range," IEEE Trans. Energy Convers., vol. 17, no. 1, pp. 79-84, Mar. 2002.

[5] T. M. Jahns, "Torque production in permanent-magnet synchronous motor drives with rectangular current excitation," IEEE Trans. Ind. Appl., vol. IA-20, no. 4, pp. 803-813, Jul./Aug. 1984.

[6] C. C. Chan, J. Z. Jiang, W. Xia, and K. T. Chau, "Novel wide range speed control of permanent brushless motor drives," IEEE Trans. Power Electron., vol. 10, no. 5, pp. 539-546, Sep. 1995.

[7] Y. Liao, F. Liang, and T. A. Lipo, "A novel permanent motor with doubly salient structure," IEEE Trans. Ind. Appl., vol. 31, no. 5, pp. 1069-1078, Sep./Oct. 1995

[8] M. Cheng, K. T. Chau, and C. C. Chan, "Design and analysis of a new doubly salient permanent magnet motor," IEEE Trans. Magn., vol. 37, no. 4, pp. 3012-3020, Jul. 2001.

[9] Y. Li and T. A. Lipo, "A doubly salient permanent magnet motor capable of field weakening," in Proc. IEEE 26th Annu. Power Electron. Spec. Conf., vol. 1, Jun. 1995, pp. 565-571.

[10] K. T. Chau, Y. B. Li, J. Z. Jiang, and S. Niu, "Design and control of a PM brushless hybrid generator for wind power application," IEEE Trans. Magn., vol. 42, no. 10, pp. 3497-3499, Oct. 2006.

[11] V. Ostovic, "Memory motors: A new class of controllable-flux permanent magnet machines for true wide-speed operation," IEEE Ind. Appl. Mag., vol. 9, no. 1, pp. 52-61, Jan./Feb. 2003.

[12] C. Yu, K. T. Chau, X. Liu, and J. Z. Jiang, "A flux-mnemonic permanent magnet brushless motor for electric vehicles," J. Appl. Phys., vol. 103, no. 7, pp. 1-3, Apr. 2008.

[13] C. Yu, K. T. Chau, and J. Z. Jiang, "A flux-mnemonic permanent magnet brushless machine for wind power generation," J. Appl. Phys., vol. 105, no. 7, pp. 1-3, Apr. 2009.

[14] L. Parsa and H. A. Toliyat, "Fault-tolerant interior-permanent-magnet machines for hybrid electric vehicle applications," IEEE Trans. Veh. Technol., vol. 56, no. 4, pp. 1546-1552, Jul. 2007.

[15] T. J. E. Miller, Switched Reluctance Motors and Their Control. Oxford: Magna Physics Publishing and Clarendon Press, 1993.

[16] G. Bertotti, Hysteresis in Magnetism: for Physicists, Material Scientists, and Engineers. San Diego, CA: Academic, 1998.

[17] S. J. Salon, Finite Element Analysis of Electrical Machines. Boston, MA: Kluwer Academic, 1995.

[18] K. T. Chau, M. Cheng, and C. C. Chan, "Performance analysis of 8/6-pole doubly salient permanent magnet motor," Electric Mach. Power Syst., vol. 27 , no. 10 , pp. $1055-1067$, Oct. 1999.

[19] K. T. Chau, C. Liu, and J. Z. Jiang, "Comparison of outerrotor stator-permanent-magnet brushless motor drives for electric vehicles," in Proc. Int. Conf. Electr. Mach. Syst., Oct. 2008, pp. 2842-2847.

[20] A. Emadi and M. Ehsani, "Aircraft power systems: Technology, state of the art, and future trends," IEEE Aerosp. Electron. Syst. Mag., vol. 15, no. 1, pp. 28-32, Jan. 2000.

[21] K. T. Chau, Q. Sun, Y. Fan, and M. Cheng, "Torque ripple minimization of doubly salient permanent-magnet motors," IEEE Trans. Energy Convers., vol. 20, no. 2, pp. 352-358, Jun. 2005. 


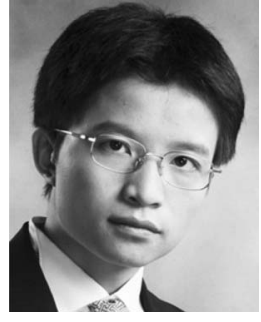

Chuang Yu received the B.Eng. and M.Eng. degrees from the Beijing Institute of Technology, Beijing, China, in 2004 and 2006, respectively, and the Ph.D. degree from the University of Hong Kong, Pokfulam, Hong Kong, in 2010, all in electrical engineering.

$\mathrm{He}$ is currently an Engineering Specialist in Johnson Electric, Shatin N.T., Hong Kong, China. His research interests include electric drives, electric vehicles, and power electronics, as well as the design, analysis and control of permanent magnet brushless motors.

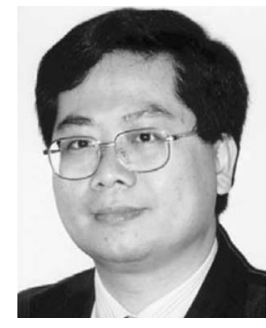

K. T. Chau (M'89-SM'04) received the B.Sc. (Eng.) (first-class honors), M.Phil., and Ph.D. degrees in electrical and electronic engineering from the University of Hong Kong, Pokfulam, Hong Kong, in 1988, 1991, and 1993, respectively.

He is currently a Professor in the Department of Electrical and Electronics Engineering, University of Hong Kong, where he is also the Director of the International Research Center for Electric Vehicles. His research interests include three main areas: electric vehicles, electric drives, and power electronics. In these areas, he is the author or coauthor of more than 200 referred technical papers. He is also the coauthor of a monograph Modern Electric Vehicle Technology (Oxford University Press, 2001).

Prof. Chau is a Fellow of the Institute of Engineering and Technology, U. K. He was the recipient of the Outstanding Young Researcher Award in 2003, the University Teaching Fellowship Award in 2004, and the Award for Innovative Excellence in Teaching, Learning, and Technology in 2005. 